\title{
First mass development of Aedes albopictus (Diptera: Culicidae) -its surveillance and control in Germany
}

\author{
Norbert Becker $^{1,2}$ (1) - Stefanie Schön ${ }^{3}$ - Alexandra-Maria Klein ${ }^{3}$ - Ina Ferstl ${ }^{1,4}$. \\ Ali Kizgin ${ }^{2} \cdot$ Egbert Tannich $^{5,6}$ - Carola Kuhn ${ }^{7}$ • Björn Pluskota ${ }^{1}$ • Artur Jöst ${ }^{1}$
}

Received: 10 November 2016 / Accepted: 15 December 2016/Published online: 23 January 2017

(C) The Author(s) 2017. This article is published with open access at Springerlink.com

\begin{abstract}
The Asian tiger mosquito Aedes albopictus has undergone a dramatic expansion of its range in the last few decades. Since its first detection in 2007 in Germany at the motorway A5 coming from Italy via Switzerland to Germany, it has been continuously introduced by vehicles, most probably from Italy. After a hint from an alert gardener in an allotment garden area in Freiburg, Southwest Germany, in 2015, a surveillance programme was started focusing on the garden area and adjacent areas as well as most of the cemeteries as potential infestation areas. The surveillance programme confirmed a high infestation of the allotment garden. The container index (CI) exceeded almost 30\% in August 2015. In lethal gravid Aedes traps (GATs) and BG-Sentinel traps, 4038 adults were caught. It could be proven that the Aedes population is more or less still spatially restricted to the allotment garden
\end{abstract}

Norbert Becker

norbertfbecker@web.de

1 Institute for Dipterology (IfD)/KABS, Georg-Peter-Süß-Str. 3, 67346 Speyer, Germany

2 Faculty of Biosciences, University of Heidelberg, Im Neuenheimer Feld 230, 69120 Heidelberg, Germany

3 Faculty for Environmental and Natural Resources, Albert-Ludwigs-University, Tennenbacher Str. 4, 79106 Freiburg im Breisgau, Germany

4 Faculty of Biology, Albert-Ludwigs-University, Hauptstraße 1, 79104 Freiburg im Breisgau, Germany

5 Bernhard Nocht Institute for Tropical Medicine, Bernhard-Nocht-Str. 74, 20359 Hamburg, Germany

6 German Centre for Infection Research, Partner site Hamburg-Borstel-Luebeck, Hamburg, Germany

7 German Environment Agency (UBA), Bötticher Str. 2, 14195 Berlin, Germany area which is adjacent to a train station where trucks from Novara, Italy, arrive loaded on trains. Outside the garden area, only a few breeding sites with developmental stages and adults were found within a radius of approximately $600 \mathrm{~m}$ from the highly infested garden area. It is most likely that Ae. albopictus females are constantly introduced as 'blind passengers' to Freiburg via trucks from Italy to Freiburg, Germany. After the first detection of the mass development of Ae. albopictus immediate and comprehensive control measures were initiated to reduce or even eliminate the Aedes population. Citizen awareness, especially of the gardeners, was increased by providing thorough information about the biology and control of Ae. albopictus. Beside environmental management, tablets based on Bacillus thuringiensis israelensis (Bti) were applied. The success of the control activities by the gardeners is reflected by the data gained during monthly inspection of the garden plots. The number of gardens without any container increased from $17 \%$ in July to 22\% in August and 35\% in September, 2015, resulting in a successful reduction of the Ae. albopictus population. The study underlines the importance of a comprehensive surveillance programme to assess the population density of Ae. albopictus as a basis for integrated control activities.

Keywords Aedes albopictus - Mass development . Surveillance and control · Germany

\section{Introduction}

The Asian tiger mosquito Aedes albopictus (Skuse, 1895), originating from Southeast Asia, has undergone a dramatic expansion of its range in the last few decades (Hawley 1988; Cornel and Hunt 1991; Moore and Mitchell 1997; Benedict et al. 2007; Medlock et al. 2012, 2015). The dispersal is 
facilitated by human activities such as increased mobility of humans as well as international trade, especially the trade with used tyres in which the females lay their eggs (Reiter and Sprenger 1987). The eggs can survive desiccation and dryness for months and thus survive long periods with unfavourable living conditions during transport. Another way of spreading eggs and larvae of Ae. albopictus is the trade with ornamental plants (Madon et al. 2004; Scholte and Schaffner 2007).

Ae. albopictus possesses a high ecological potency and can rapidly adapt to new habitats due to its genetic plasticity. This species has spread from tropical regions to areas with temperate climates which do not allow a constant follow-up of generations, e.g. during winter periods. As a consequence, the species goes through a winter diapause during which the larvae in the eggs are not able to hatch and remain in the eggshell until the living conditions allow further development. Another important behavioural factor that favours the spread is that $A e$. albopictus has no strict host preference for blood meals. Adult females predominantly feed on humans but may also bite other mammals including rabbits, dogs, cows and squirrels or occasionally avian hosts. This feeding behaviour indicates that Ae. albopictus is well suited for transmitting a variety of arboviruses that use mammals and birds as their main hosts (Mitchell 1995; Gratz 2004).

In Europe, Ae. albopictus was first detected at the end of the 1970s in Albania; however, the massive spread started when Ae. albopictus was introduced to Italy by used tyres (Adhami and Reiter 1998; Sabatini et al. 1990). Within a few years, the species was established from the north of Italy to Sicily in the south, supported by the wide-scale distribution of used tyres and dispersal by vehicles (Dalla Pozza and Majori 1992; Romi 1994; Roiz et al. 2008). Once established in Italy, the species mainly spread by vehicles, trains or boats to neighbouring countries such as France (French Riviera), Croatia, Spain, Switzerland and across the Alps into Germany (Pluskota et al. 2008; Becker et al. 2012). To date, Ae. albopictus has been recorded in 26 European countries (Medlock et al. 2012, 2015).

Ae. albopictus is a competent vector of at least 23 arboviruses including Chikungunya, dengue, Zika and yellow fever virus. It has become the most important vector for the Chikungunya virus. In 2007, Ae. albopictus was for the first time involved in a small outbreak of Chikungunya fever in the Emilia-Romagna region caused by the tropical virus which was introduced by an infected tourist from India (Pfeffer and Loescher 2006; Reiter et al. 2006; Angelini et al. 2007; Beltrame et al. 2007; Rezza et al. 2007).

As a consequence of this rapid spread of Ae. albopictus in the Mediterranean area and the increased public health risk, the German Mosquito Control Association (KABS) started in 2005 a monitoring programme from Basel to Heidelberg along motorway A5 (E35) coming from Italy as a suspected port of entry for Ae. albopictus adults. It was assumed that cars, trailers or trucks coming from Italy across the Alps import Ae. albopictus to Germany. During the first monitoring programme, along motorway A5 (E35) from Basel to Heidelberg in the period of 2005 to 2009, Ae. albopictus eggs were found for the first time in an ovitrap at a resting station north of the city of Weil (Pluskota et al. 2008).

In order to assess the risk for the introduction of Ae. albopictus, a collaboration of scientific, traffic and governmental institutions in close cooperation with the public was initiated. The goal is to start control activities immediately when a population of Ae. albopictus is identified and to investigate the ports of entry to avoid further introductions (ECDC 2012; EMCA-WHO 2013). In autumn 2014, a private person reported 'strange' mosquitoes in an allotment garden area in Freiburg. Accordingly, a local surveillance and control programme was started in 2015 to prove the occurrence and distribution of Ae. albopictus as well as to determine the size of the population. The results indicated the first mass development of Ae. albopictus in Germany. Here, we report also on the immediate control activities that were conducted to eliminate or at least reduce the population according to a particular action plan.

\section{Material and methods}

\section{Surveillance}

An essential part of the action plan was the surveillance programme to assess the population density, distribution and phenology of Ae. albopictus. The surveillance programme has the following goals:

1. Assessment of the way of introduction to prohibit or reduce further introductions

2. Monitoring of the adult Ae. albopictus population by employing different trapping techniques

3. Assessment of the container index (CI) at least on a monthly basis

Special attention was paid to the railway station in Freiburg where trucks are reloaded from trains coming from Italy. Trucks are loaded onto trains in Novara in Italy, where Ae. albopictus is abundant, and reloaded at the terminal in Freiburg. Approximately 60 trains, each with up to 24 trucks, arrive weekly in Freiburg after passing through the Alps nonstop. It was assumed that Ae. albopictus is continuously being introduced by these trucks and escaping from the truck cabins at the terminal to infest the adjacent areas. An allotment garden area (Hettlinger) and a waste disposer including stored used tyres are located close to the terminal, both providing ideal breeding conditions for Ae. albopictus. The same is true for the main cemetery of Freiburg which is also located in the 
vicinity of the terminal. Besides the allotment garden area, the surroundings of the railway terminal including private properties and industrial areas as well as cemeteries were monitored citywide (Fig. 1).

\section{Trapping of Aedes albopictus}

The following traps were employed in this study to assess the population density and phenology of Ae. albopictus:

1. BG-Sentinel trap. The BG-Sentinel trap mimics convection of artificial skin emanations which can be found on human skin (ammonia, lactic and caproic acid). The efficacy of the trap was increased by the release of carbon dioxide from a gas bottle and an outlet above the black catch pipe. The release rate was $20 \mathrm{~g} \mathrm{CO}_{2} / \mathrm{h}$. The traps were usually positioned to protect them against wind, rain or direct sunlight (Biogents 2016a).

2. GAT. The GAT (gravid Aedes trap; Biogents 2016b) is a lethal trap which attracts gravid Ae. albopictus female mosquitoes searching for an oviposition place. A black plastic container in the lower part of the trap was filled with hay infusion which attracts females searching for a water body for egg deposition. The hay infusion was prepared by the suspension of $50 \mathrm{~g}$ of hay per litre for $48 \mathrm{~h}$. After the female entered the trap through a black funnel, it was trapped inside in a net treated with the pyrethroid alpha-cypermethrin. The trapped female was killed by contact with the insecticide-treated net. Usually, the traps were placed at shaded sites.

\section{Set-up of the trapping activities}

1. Allotment garden area and adjacent waste disposer. Two BG-Sentinel traps were placed in the allotment garden area where the main infestation was detected during assessment of the CI. One trap was located at the garden restaurant and one in a garden plot about $90 \mathrm{~m}$ from the restaurant. Additional to the $2 \mathrm{BG}$ traps, 40 GATs were placed in transects covering the whole garden area of about 5 ha (Fig. 2). At the adjacent waste disposer, an additional three GATs (Re1-3) were located. The traps were numbered and positioned at shaded locations at a distance of 25-50 $\mathrm{m}$ from each other. All traps were checked on a weekly basis; the numbers of captured Ae. albopictus were recorded after species determination by morphological characteristics (Becker et al. 2010) or the species was confirmed by PCR sequencing the mitochondrial cytochrome oxidase subunit 1 (CO1) gene when individuals were denudated (Folmer et al. 1994).

2. Cemeteries. Two BG-Sentinel traps were placed in the adjacent main cemetery less than $1 \mathrm{~km}$ from the allotment garden area. One additional BG-Sentinel trap was located at another cemetery (Bergäcker) about $5 \mathrm{~km}$ south-east of the allotment garden area where a small population of Ae. albopictus was found (Werner and Kampen 2015). The traps were checked on a weekly basis for Ae. albopictus.

Fig. 1 Locations of monitoring in Freiburg

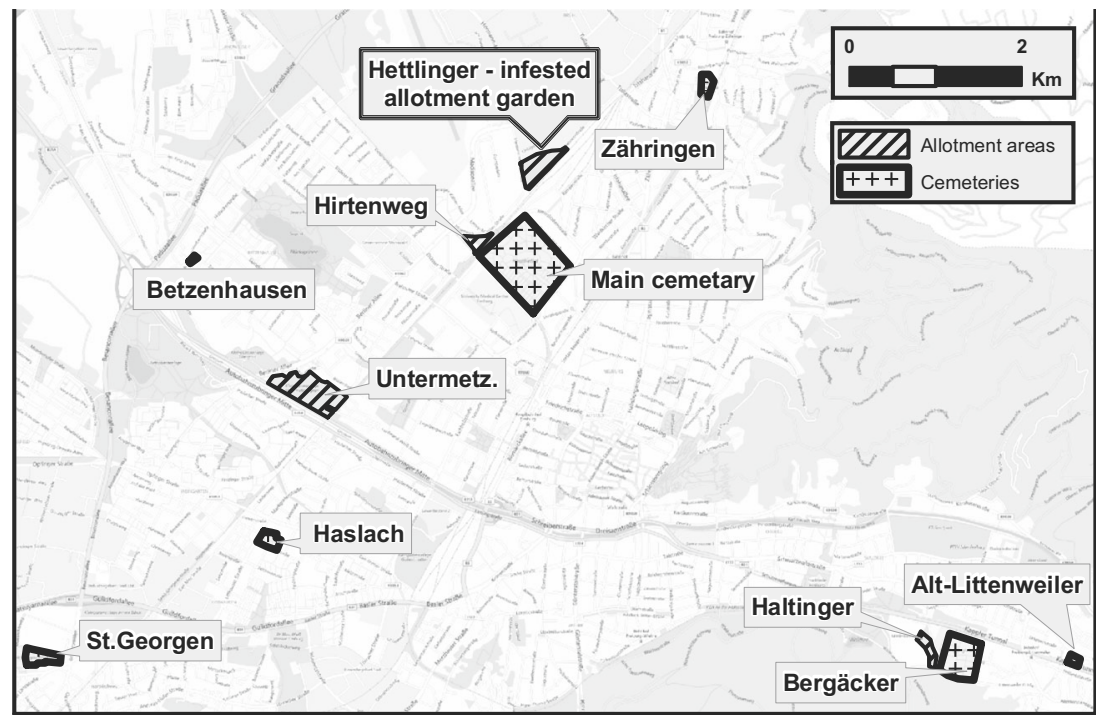


Fig. 2 Positions of GATs in the allotment garden area and at the waste disposer

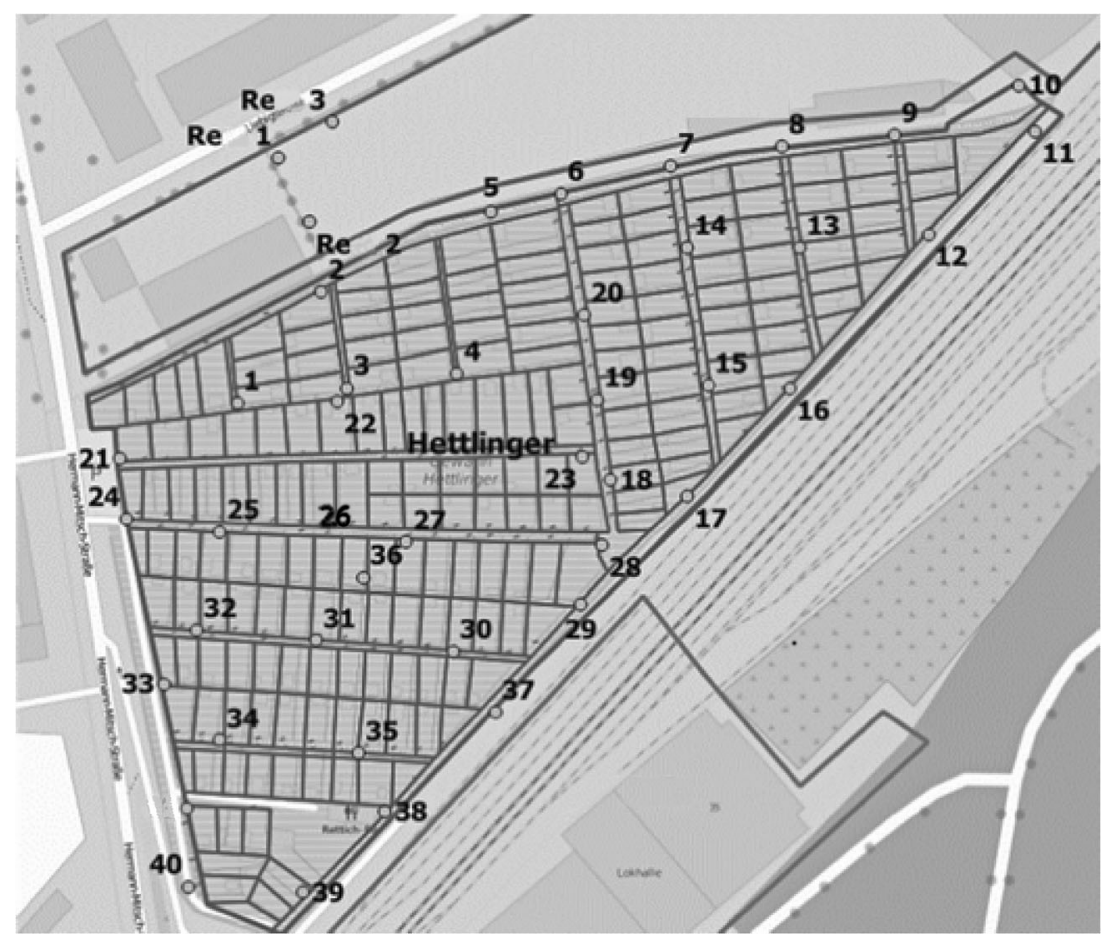

\section{Sampling of developmental stages}

Assessment of the container index in the garden area The infestation of water bodies such as rainwater barrels, buckets, watering cans, flower vases, bird baths or saucers with developmental stages of Ae. albopictus was assessed in the whole allotment garden area once a month from July to September 2015. The water bodies were usually inspected by using a torch, and the developing stages were collected with a net for precise determination in the laboratory after Becker et al. (2010). The gardeners were asked to open their garden plots for the inspections. Unfortunately, more than $20 \%$ of the garden plots were not accessible due to the absence of the gardeners and locked plots. The presence or absence of developing stages was recorded and the CI was calculated.

Extended surveillance of the mass breeding sites citywide with special consideration of the areas surrounding the allotment garden area Extended surveillance activities in the surroundings of the garden area were carried out to define the spread of the Ae. albopictus population. Within a radius of $1000 \mathrm{~m}$ from the garden area, four adjacent residential areas and an industrial area as well as the main cemetery of the city of Freiburg were inspected by five groups, each of two people. In private properties, all possible breeding sites, e.g. rainwater containers in garden areas, as well as public water collections, e.g. water catch basins along the streets and grave vases in the cemetery, were monitored for developing stages of $A e$. albopictus. Detected breeding sites have been controlled with fizzy tablets based on Bacillus thuringiensis israelensis (Bti) or have been eliminated.

Besides the intensive monitoring of the surroundings of the allotment garden area, a total of seven cemeteries and three garden areas were inspected as expected mass breeding sites. Special attention was drawn to two additional cemeteries due to the records of developmental stages reported in the year 2014 (Werner and Kampen 2015).

\section{Control of Ae. albopictus}

Control activities were carried out in close cooperation and thorough flow of information with the federal and local government as well as the city authorities and the health department. The involvement of the public was a crucial element of the programme. The control activities focused on the following goals:

Control of Ae. albopictus by environmental management through community participation

An essential element of our control operation was environmental management based on community participation. The awareness of control activities by the garden plot owners and inhabitants of the surrounding settlements was increased by the distribution of flyers, fixing of information boards at the entrances of the gardens and cemeteries as well as during several information events. Thorough information on the biology and control of Ae. albopictus was provided to give 'help for self-help' and to transform the public from 'spectators' to 'actors' (Becker 1992). 
The following control measures were proposed: eliminate unnecessary water bodies; collect, recycle and dispose of unnecessary containers and waste; empty, clean and refill drums, vases, bird baths, etc. on a weekly basis; use waterproof covers for drums, tanks or cisterns; lids or nets have to cover the openings of containers completely to avoid mosquito females laying eggs; storage buckets, water cans and other artificial containers under roofs to avoid the collection of rain water. The implementation of recommendations by the gardeners and house residents was checked by inspections on a monthly basis from July to September.

\section{Control of Ae. albopictus by Bti fizzy tablets}

Water containers which could not be modified by sanitation were treated with Culinex Tab plus (Bti fizzy tablets) to eliminate the larvae. The tablets were provided free of charge in the frame of community participation. The $550 \mathrm{mg}$ tablets (Culinex Tab plus, lot no.: D13119, registration no. DE-0003009-18) have a potency of $1000 \mathrm{ITU} / \mathrm{mg}$ and contain VectoBac WG (Valent BioSciences, Chicago, USA). The tablets develop a fizzy effect in water and dissolve automatically. The Bti fizzy tablets kill only nematoceran flies and do not harm other organisms. Therefore, they are well suited for community participation (Becker et al. 1991; Becker 1992; WHO 1999).

Before operational use, the efficacy of the tablets against Ae. albopictus was assessed in bioassays and in semi-field tests.

1. Assessment of the LC values of the tablets in bioassays against Ae. albopictus. In the laboratory, bioassays were conducted according to the WHO guidelines for bioassays with some modifications (WHO 1981; Skovmand and Becker 2000). Three Bti fizzy tablets were ground to a powder and homogenized; $50 \mathrm{mg}$ of the powder was poured into a $20-\mathrm{mL}$ flask with $10 \mathrm{~mL}$ of deionized water and homogenized for $10 \mathrm{~min}$ with a vortex. From this initial solution, the basal solution $(50 \mathrm{mg} / \mathrm{L})$ was prepared: $0.2 \mathrm{~mL}$ of the initial solution was added to $19.8 \mathrm{~mL}$ of deionized water and agitated on a vortex at maximum speed. According to the results of a range-finding bioassay, the final concentrations were $0.04,0.03,0.02,0.01$ and $0.005 \mathrm{mg} / \mathrm{L}$ in $150 \mathrm{~mL}$ of deionized water. Four cups were used for each concentration and four cups served as control. In each cup, 25 early fourth instar larvae of Ae. albopictus were added. The mortality rate was assessed 24 and $48 \mathrm{~h}$ p.a. by counting dead and living larvae. The tests were repeated twice. The mortality data were corrected according to Abbott's formula (Abbott 1925). The results were subjected to log-probit analysis (Finney 1971). The temperature during the test period was $26 \pm 1{ }^{\circ} \mathrm{C}$; the light-dark period was $16: 8 \mathrm{~h}$.
2. Assessment of the efficacy of Culinex Tab plus (Bti fizzy tablets) against Ae. albopictus in semi-field tests. In semifield tests, rainwater containers (volume: each $220 \mathrm{~L}$ ) holding $200 \mathrm{~L}$ of tap water were positioned in two rows in a shaded garden area in a district close to Heidelberg where Ae. albopictus is abundant. Twenty containers were treated with Bti fizzy tablets at 2 different dosages. In the first series, ten containers were filled with $200 \mathrm{~L}$ of tap water, and in each of five containers, one Bti fizzy tablet/100 L or two Bti fizzy tablets/100 L (recommended dosage) were randomly applied. In the second series, the same set-up was used; however, in each container, $1 \mathrm{~L}$ of water with debris deriving from a natural rain gutter was added to $199 \mathrm{~L}$ of tap water. The natural debris was dissolved in $10 \mathrm{~L}$ of water. One litre of the suspension was added to each of the containers of the second series. Each of five containers was treated either with one or two Bti fizzy tablets/100 L. Three containers served as controls. All containers were covered with tight lids to simulate conditions similar to those barrels completely closed for storing water at homes or allotment gardens. Temperature, $\mathrm{pH}$ and conductivity were measured in each container.

Twenty-five third instar larvae of Ae. albopictus were released at 3-day intervals into each of the containers. The larvae derived from natural populations in Heidelberg-Wieblingen. Living larvae were removed and counted $72 \mathrm{~h} \mathrm{p}$.a. to calculate the mortality. Then, 25 fresh third instar larvae were added to each container. The tests were conducted until the mortality was less than $80 \%$ in one of the containers.

The experiment was conducted at a mean ambient temperature of $27.5^{\circ} \mathrm{C}\left(18.3-35.9{ }^{\circ} \mathrm{C}\right)$ and a water temperature of $26^{\circ} \mathrm{C}\left(18.4-32.9^{\circ} \mathrm{C}\right)$. The $\mathrm{pH}$ varied between 6.9 and 7.3 and the conductivity between 785 and $791 \mu \mathrm{S}$ during the test.

\section{Use of GATs to reduce the Ae. albopictus population}

Besides the use of GATs for monitoring purposes, the efficacy of the lethal GATs to control an Ae. albopictus population was assessed in the allotment garden area. The hypothesis was that the Aedes population could be significantly reduced by constant elimination of gravid females. Forty traps were numbered and placed in transects covering the whole garden area from July to October 2015 (Fig. 2). The traps were positioned in shaded areas at a distance of $25-50 \mathrm{~m}$. Numbers of captured Ae. albopictus were recorded on a weekly basis.

\section{Reduction of Aedes eggs by cleaning the water barrels}

In addition to the control activities during the 2015 season, we aimed to reduce the overwintering larvae in eggshells in spring 2016 before the reproduction period started. 
From the beginning of March 2016, a cleaning campaign in the garden area was conducted. All 62 accessible rain barrels in the affected areas used as artificial breeding sites by $A e$. albopictus were thoroughly cleaned with scrubbing brushes each for about $5 \mathrm{~min}$ to remove diapause eggs deposited on the inside of the barrels. The eggs of Ae. albopictus are fairly robust and thus can remain intact even after being subjected to the scrubbing process. The debris of each container was filtered through a textile net (white sock) and macroscopically examined by means of binoculars for existing eggs in a whitish plastic pan $(20 \mathrm{~cm} \times 20 \mathrm{~cm})$. Then, the plastic trays containing eggs were filled with $1 \mathrm{~L}$ of tap water (temperature $25 \pm 1^{\circ} \mathrm{C}$ ) for larval hatching. The hatched larvae from each container were reared to the fourth instar for precise species determination. The effect of the cleaning process was checked during the following time period by inspection of the containers for larval development.

\section{Statistics}

The statistical analysis and graphical documentation was done in SigmaPlot (version 13.0, Systat Software Inc., San Jose, California, USA). The trapping data were tested for normality with a Shapiro-Wilk test and if normality was not given, nonparametric one-way analysis of variance (ANOVA) on ranks by Kruskal-Wallis was performed. Significant differences were approved by Dunn's test. For the comparison of expected and observed frequencies, a chi-squared test was performed with a threshold value for significant differences of $p \leq 0.05$.

The mortality rate in the bioassays was corrected according to Abbott's formula (Abbott 1925). The results were subjected to log-probit analysis (Finney 1971, Raymond 1985), and the data were treated by Duncan's multiple range test and Student's $t$ test (Köhler et al. 1984).

In the semi-field test, the mortality rates were compared by one-way ANOVA followed by Duncan's multiple range test.

Fig. 3 Total number of Aedes albopictus adults per trap (nos. $1-$ 40) from the end of July to the end of October 2015

\section{Results}

\section{Surveillance}

\section{Trapping of adults}

In the course of the surveillance programme, it was proven that a large population of Ae. albopictus developed in the garden area in 2015. A total of 3807 adults were trapped between July and October 2015, namely 847 adults in the two BG traps and 2960 adults in the 40 GATs. Additionally, in the adjacent waste disposer, 231 individuals were caught in 3 GATs (Re 1-3) from August to October 2015.

In comparison to the garden area, only a few individuals of Ae. albopictus (five individuals) were caught in the BG traps at the main cemetery. At all other cemeteries within the larger area, no adult Ae. albopictus females were detected.

In Fig. 3, the total number of individuals per GAT in the time period from 27th July to 25 th October 2015 is presented. The highest number of more than 600 individuals was caught in trap 8 , followed by trap 10 . Both are close to the used tyre deposit at the waste disposer. Most of the other traps caught between 100 and 200 individuals in 3 months, altogether amounting to 2960 individuals.

\section{Container index (CI) at the allotment garden area}

The developing stages of Ae. albopictus were sampled in July, August and September 2015. The following spots were examined: in July, 89 garden plots including 190 containers; in August, 151 garden plots including 307 containers and in September, 112 garden plots including 186 containers. The following containers were positive: in July, 35 out of the 190 containers; in August, 91 out of 151 containers and in September, 12 out of the 112 containers, which corresponds to a CI of $18.42 \%$ in July, $29.64 \%$ in August and $15.05 \%$ in September (Fig. 4).

\section{Total catch Ae. albopictus - Adults/GAT}

27.7.-25.10.15

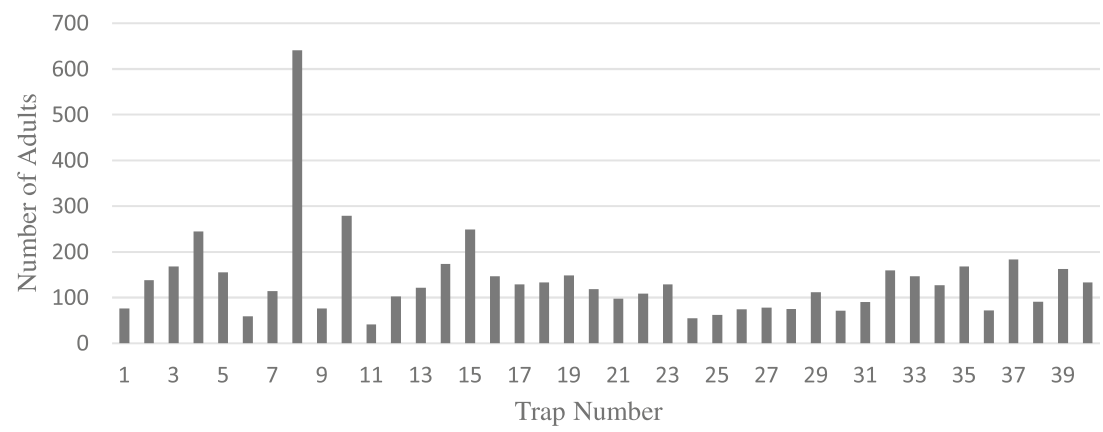




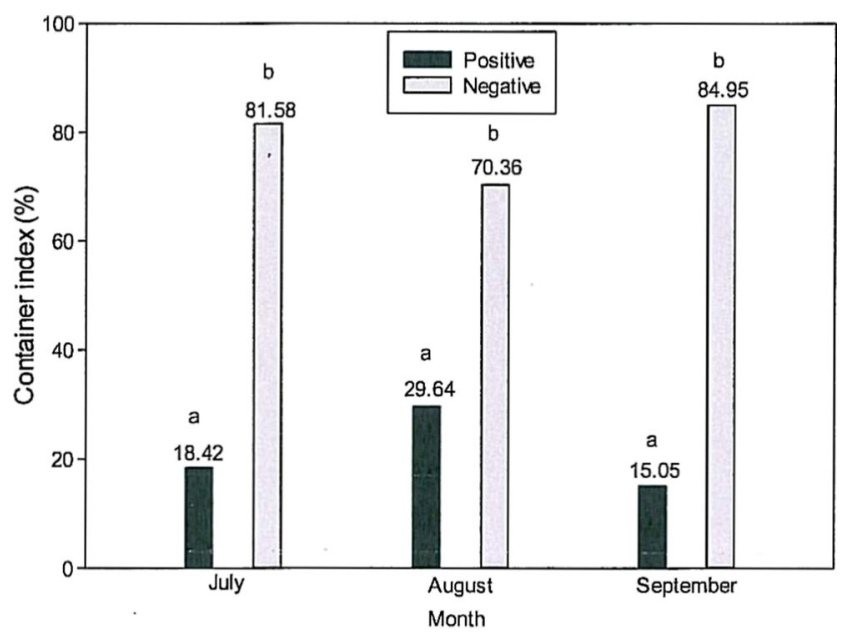

Fig. 4 Container indices (CI) (\%: positive in black, negative in grey) in July, August and September 2015. Significant differences $(p \leq 0.05)$ are indicated by different letters $(a, b)$

\section{Extended surveillance}

In the extended surveillance area at nine sites, developing stages and adults of Ae. albopictus could be recorded, not more than $600 \mathrm{~m}$ from the mass breeding sites. In the residential areas, a water catch basin and two rainwater containers with developing stages of Ae. albopictus were identified. In the industrial areas, two adults and at the waste disposer developing stages were found in used tyres as well as biting adults. In the main cemetery, one grave vase was infested with larvae of Ae. albopictus and in the two BG-Sentinel traps three adults were caught. In a garden area, one rainwater container with developing stages was recorded.

\section{Effect of the control activities}

\section{Reduction of the breeding sites by environmental management through community participation}

Thorough information of the gardeners resulted in a steady reduction of breeding sites in the garden plots by elimination of water-holding bodies. Inspected gardens without any containers increased from 17\% in July to 22\% in August and 35\% in September. The encouragement of the gardeners to avoid egg laying by gravid Ae. albopictus females in rainwater containers by using tight lids, mosquito nets or taping of gaps in the coverage was well accepted. After the maximum abundance of Ae albopictus in the GATs in the 33rd week, the number of Ae. albopictus never reached this level afterwards. It is striking that the second peak in the 36th week did not exceed the numbers during the 33rd week, even though the conditions of development were ideal for Ae. albopictus (mean temperature week $34-3619.4^{\circ} \mathrm{C}$; minimum temperature $8.3{ }^{\circ} \mathrm{C}$; precipitation $31.6 \mathrm{~mm}$ ). From the 36 th week, the number of trapped Ae. albopictus steadily declined (Fig. 5).

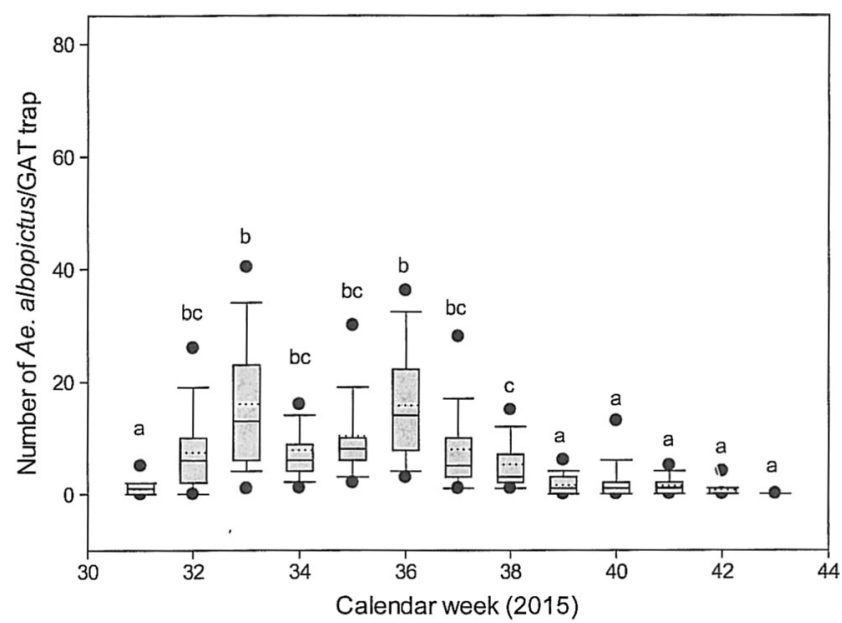

Fig. 5 Number of Ae. albopictus adults per GAT from week 30 to week 43. Significant differences $(p \leq 0.05)$ are indicated by different letters $(a, b$ and $c$ )

\section{Effect of Culinex Tab plus (Bti fizzy tablets)}

1. Bioassays. The bioassays with early fourth instar larvae of Ae. albopictus revealed an $\mathrm{LC}_{50}$ value of $0.0149 \mathrm{mg} / \mathrm{L}$ and an $\mathrm{LC}_{90}$ value of $0.03558 \mathrm{mg} / \mathrm{L}$ (Fig. 6).

2. Semi-field tests. In the first series with tap water, the mortality was $100 \%$ for 15 days when the recommended dose of one tablet $/ 50 \mathrm{~L}(11 \mathrm{mg} / \mathrm{L})$ was applied and $94.4 \%$ when half of the dosage $(5.5 \mathrm{mg} / \mathrm{L})$ was applied. After 24 days, the mortality rates were still 96.8 and $89.6 \%$, respectively.

In the second series with tap water and organic material from the rain gutter, the mortality was $98.4 \%$ at each dosage

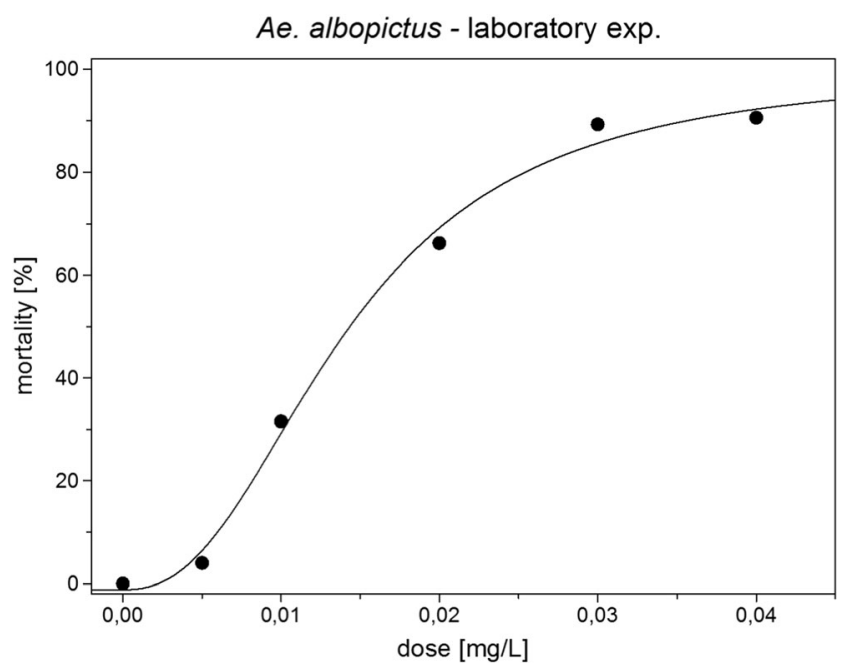

Fig. 6 Dose-response curve of early fourth instar larvae of Aedes albopictus to Culinex Tab plus (Bti fizzy tablets) 
Table 1 Efficacy of Culinex Tab plus tablets (\%) at dosages of $5.5 \mathrm{mg} / \mathrm{L}$ (one tablet/100 L) and $11 \mathrm{mg} / \mathrm{L}$ (two tablets/100 L) with and without organic material in semi-field tests

\begin{tabular}{|c|c|c|c|c|c|c|c|}
\hline \multirow{2}{*}{$\begin{array}{l}\text { Application } \\
\text { (Days) }\end{array}$} & \multirow{2}{*}{$\begin{array}{l}\text { (n) Total } \\
\text { (Larvae) }\end{array}$} & \multicolumn{6}{|l|}{ Dead larvae \% } \\
\hline & & $\mathrm{CX}^{\mathrm{a}}(5.5 \mathrm{mg} / \mathrm{L})$ & $\mathrm{CX}(5.5 \mathrm{mg} / \mathrm{L})$ & $\mathrm{CX}^{\mathrm{a}}(11 \mathrm{mg} / \mathrm{L})$ & $\mathrm{CX}(11 \mathrm{mg} / \mathrm{L})$ & $\mathrm{CX}^{\mathrm{a}}(22 \mathrm{mg} / \mathrm{L})$ & Control \\
\hline 0 & 625 & - & - & - & - & - & - \\
\hline 3 & 625 & $100 \pm 0$ & $100 \pm 0$ & $100 \pm 0$ & $100 \pm 0$ & $100 \pm 0$ & $24 \pm 31,749$ \\
\hline 6 & 625 & $100 \pm 0$ & $100 \pm 0$ & $100 \pm 0$ & $100 \pm 0$ & $100 \pm 0$ & $9,3 \pm 6,110$ \\
\hline 9 & 625 & $99,2 \pm 1,789$ & $99,2 \pm 1,789$ & $99,2 \pm 1,789$ & $100 \pm 0$ & $100 \pm 0$ & $0 \pm 0$ \\
\hline 12 & 675 & $95,1 \pm 1,789$ & $96,6 \pm 3,578$ & $98,3 \pm 2,191$ & $100 \pm 0$ & $100 \pm 0$ & $3,2 \pm 9,237$ \\
\hline 15 & 625 & $95,1 \pm 2,191$ & $94,2 \pm 6,066$ & $98,3 \pm 3,578$ & $100 \pm 0$ & $98 \pm 2,828$ & $2,6 \pm 2,309$ \\
\hline 18 & 625 & $93,6 \pm 4,561$ & $95,2 \pm 3,347$ & $95,2 \pm 4,382$ & $99,2 \pm 1,789$ & $100 \pm 0$ & $0 \pm 0$ \\
\hline 21 & 625 & $83,2 \pm 7,155$ & $87,2 \pm 7,694$ & $89,6 \pm 2,109$ & $96,8 \pm 3,347$ & $96 \pm 0$ & $0 \pm 0$ \\
\hline 24 & 625 & $80 \pm 4$ & $89,6 \pm 3,578$ & $88 \pm 2,828$ & $96,8 \pm 3,346$ & $98 \pm 2,828$ & $0 \pm 0$ \\
\hline
\end{tabular}

${ }^{\mathrm{a}}$ Water container loaded with organic material

of one $(5.5 \mathrm{mg} / \mathrm{L})$ or two tablets $(11 \mathrm{mg} / \mathrm{L})$ after 15 days. After 24 days, the mortality rates were 80 and $88 \%$ when one or two tablets/100 L were applied, respectively. The mortality in the control was between 0 and $9.3 \%$ between days 6 and 24 (Table 1 and Fig. 7). The slightly higher mortality rate of $24 \%$ in the first 3 days was attributed to the acclimatization of the released larvae to the fresh water bodies.

Duncan's multiple range test proved high significant differences $(p<0.05)$ between the groups with concentrations of 0.0055 and $0.011 \mathrm{mg} / \mathrm{L}$ as well as between groups with and without organic material 21 days p.a.

A total of 167 containers infested with Ae. albopictus developmental stages were eliminated or treated with Bti tablets. Based on the observations, the use of one tablet per $50 \mathrm{~L}$ of water on a bi-weekly basis provided $100 \%$ control of larvae.

\section{Cleaning of rainwater containers}

Out of the 62 scrubbed rainwater containers, eggs could be found in 35 containers $(56.45 \%)$. All hatched larvae could be determined as Ae. albopictus. Larvae could be found in none of the cleaned and re-filled containers in the following 8 weeks of observation in April and May 2016.

\section{Discussion}

This is the first detection of mass development of Ae. albopictus in Germany. We define mass development when the $\mathrm{CI}$ is $>20 \%$; biting adults and several thousand developing stages could be found in a large infested area ( $>3$ ha). Immediate and comprehensive control measures were implemented to reduce or even eliminate the population. The surveillance programme in 2015 confirmed a high infestation of an allotment garden area; however, the Aedes population was still more or less spatially restricted to the allotment garden area which is adjacent to a train station where trucks are unloaded from trains arriving from Novara, Italy. Outside the garden area, in the adjacent industrial and residential areas as well as in the main cemetery development stages and a few biting adults were detected only in a few breeding sites such as rainwater containers, water catch basins and vases, but only in a range of not more than approximately $600 \mathrm{~m}$ from the allotment garden area. This confirms the limited active spread of Ae. albopictus (Becker et al. 2010). It is most likely that Ae. albopictus females are constantly introduced as 'blind passengers' to Freiburg via trucks. More than 20 trucks can be loaded onto each train in Novara, Italy, an area which is highly infested by Ae. albopictus (A. Mosca, personal communication). Each day, more than 100 trucks are transported non-stop by at least 6 trains to Freiburg. It is known that nonblood-fed Ae. albopictus females aggressively follow their hosts when they search for a blood meal. Thus, they may enter the driver's cabin or the accompanying passenger coach in

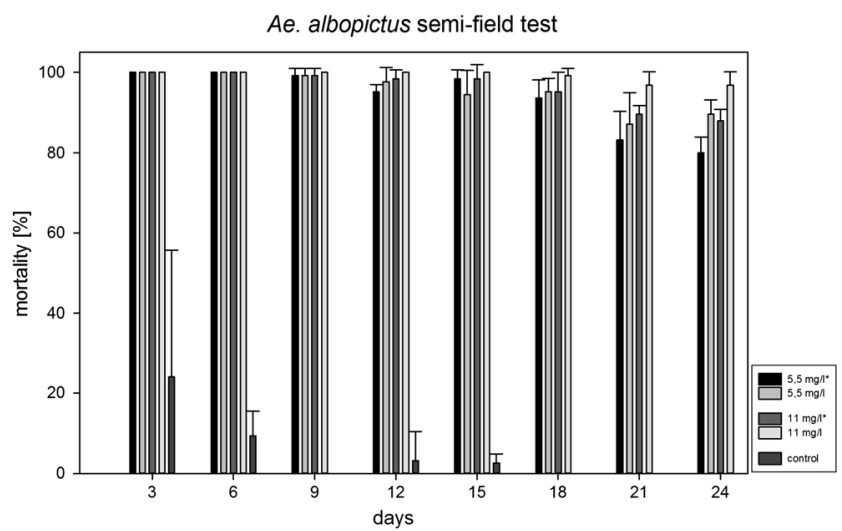

Fig. 7 Efficacy of Culinex Tab plus tablets in semi-field tests at dosages of $5.5 \mathrm{mg} / \mathrm{L}$ (one tablet $/ 100 \mathrm{~L}$ ) and $11 \mathrm{mg} / \mathrm{L}$ (two tablets $/ 100 \mathrm{~L}$ ) with and without organic material (bars are SD) 
Novara and are released when the cabin is opened after arrival in Freiburg. In the adjacent allotment garden area which is less than $20 \mathrm{~m}$ away from the railway station Ae. albopictus females find ideal conditions for reproduction, namely a large number of artificial containers such as rainwater containers, water-filled buckets, watering cans or flower pot saucers as well as hosts for blood meals, flowers for sugar meals and bushes as resting zones. Furthermore, the establishment of the species is favoured by the climatic conditions in Freiburg (Pluskota 2011).

The limits for population establishment in Germany are a mean air temperature in January above $-3{ }^{\circ} \mathrm{C}$ and a mean temperature of the three warmest months (June, July and August) above $19{ }^{\circ} \mathrm{C}$ as well as minimum precipitation of $500 \mathrm{~mm}$ (Pluskota 2011). In Freiburg, temperature and precipitation measured in the period of 1990 to 2015 were above these thresholds: the January mean air temperature was $2.9^{\circ} \mathrm{C}$, and the mean temperature of the three warmest months (19$20.9^{\circ} \mathrm{C}$ ) and the annual precipitation at $890 \mathrm{~mm}$ exceed the minimum threshold (DWD 2016). The regular introduction of Ae. albopictus, the high number of available breeding sites and high summer temperatures for several weeks promoted high population growth within the 'founder population'. A clear sign of successful establishment was the first demonstration of successful overwintering in Germany in spring 2016 (Pluskota et al. 2016). Most authors assume that the thermal conditions during the overwintering of diapausing embryos in the eggs are the limiting factor (Nawrocki and Hawley 1987; Knudsen 1995; Mitchell 1995; Medlock et al. 2006; ECDC 2009; Takumi et al. 2009). However, studies on the thermal ecology of Ae. albopictus revealed that the most important factors for the permanent establishment of the species in Germany are the temperatures occurring during the summer months (Pluskota 2011). In recent years, the average temperatures have risen continually by approximately $1.4^{\circ} \mathrm{C}$ in both the summer months as well as in the winter months (Becker 2008). This increases the possibility of successful establishment of Ae. albopictus in Germany and makes a continuous surveillance programme and efficient control efforts essential to avoid circumstances as in the Mediterranean area.

Our goal is either to eradicate Ae. albopictus or at least to reduce the population to a threshold that does not expose the public to an increased health risk or to reduce the nuisance caused by Ae. albopictus. It was important to immediately introduce control activities when the reproduction of Ae. albopictus was confirmed. The success of control measures has been documented in the course of a strict monitoring programme. One of the strongest assets for fighting containerbreeding mosquitoes is the participation of the community (Becker 1992). Information given to the public about the biology of Ae. albopictus and suitable control measures as well as 'door-to-door' actions contributed to the decline of the mosquito population. The encouragement of the gardeners to eliminate unnecessary breeding sites, to store buckets or cans under a roof or to turn them upside down, so that no rainwater could be collected as well as modification of the breeding sites such as tight coverage of the containers with mosquito nets or well-fitting lids along with taping small gaps in the coverage was very much accepted. Furthermore, a total of 167 containers infested with Ae. albopictus developmental stages were eliminated or successfully treated with Bti fizzy tablets. According to the observations, one $550 \mathrm{mg}$ tablet with an activity of $1000 \mathrm{ITU} / \mathrm{mg}$ was enough to treat $50 \mathrm{~L}$ of water with a killing effect for at least 2 weeks. Similar results were obtained in studies in Indonesia (Becker et al. 1991) and in Columbia by Kroeger et al. (1995). The tablets are safe for the applicant and the Bti-treated water can still be used as potable water (WHO 1999).

The success of the control activities by the gardeners is reflected in the data gained by the monthly inspection of the gardens. The number of gardens without any containers increased from $17 \%$ (July) to 22\% (August) and 35\% in September.

However, the CI increased from $18.4 \%$ in July to $29.6 \%$ in August. The increase of the CI could be partly explained as not all gardeners participated in the control activities and some gardens were not accessible due to the permanent absence of the gardeners and locked garden plots. Furthermore, coverage of the containers was sometimes not appropriate due to gaps in the lids, especially small dark holes which attract females to enter the container because it mimics the situation given by tree holes.

Sensitization and public awareness of control of containerbreeding mosquitoes takes time. It is likely that the results obtained in 2016 will be more satisfactory due to early information campaigns. Community participation is the most effective tool but is hard to sustain in the fight against containerbreeding mosquitoes. A decrease of the CI can be induced by climatic features like lower temperatures and reduced day length (Roiz et al. 2011). Romi (1995) and Toma et al. (2003) showed that the production of summer eggs ceased when the temperature dropped below $10^{\circ} \mathrm{C}$. The mean temperature in September was $13.26^{\circ} \mathrm{C}$.

The positive effect of the control efforts is well documented in Fig. 5. After the first population peak in the $33 \mathrm{rd}$ week, it could be assumed that the second peak in the 36th week would be much higher than the first peak. The population reduction from the 33rd week on was caused by control activities like the elimination and modification of the breeding sites, the reduction of the Aedes population by the massive use of GATs and the use of Bti fizzy tablets. In total, 4038 Ae. albopictus females were caught, especially by GATs (3191 adults). According to Gubler and Bhattacharya (1971) and Hawley (1988), a female lays 300 eggs during its lifespan. Thus, the development of several hundred thousand Ae. albopictus offspring in the garden and 
adjacent waste disposer could be avoided. It could be proven that the lethal GATs can be used as an additional tool to reduce an adult Ae. albopictus population. The traps have to be deposited in sufficient numbers at an appropriate distance of about $25 \mathrm{~m}$ or less.

The evaluation and control of the Ae. albopictus population has continued in 2016 to assess the effect of control efforts based on the results of 2015 and under the consideration of an earlier start of control activities compared to 2015. It turned out that cleaning the containers is a useful additional measure to reduce the starting population of Ae. albopictus. None of the 62 rainwater containers which were cleaned by brushing was infested with larvae till May 2016. Thus, the effectiveness of appropriate container cleaning could be proven to combat Ae. albopictus in Germany. Similar results have been achieved in Thailand (Phuanukoonnon et al. 2005).

In future years, the sterile insect technique (SIT) and the use of Wolbachia-based strategies will be employed to overcome the problem that not all garden plots can be inspected due to the absence or ignorance of the gardeners. We aim to reduce the natural Ae. albopictus population by all traditional tools to a level with as few 'wild' males as possible survive the control activities. Then, a sufficient number of sterilized or Wolbachia-infected males will be released over a sufficiently extended period, so that they outcompete the indigenous males in terms of mating. The males will be either sterilized by gamma radiation (35 Gy) or infected with Wolbachia, a bacterial symbiont which leads to cytoplasmic incompatibility. If a female mosquito mates with a sterile or Wolbachia-infected male, the female will lay only sterile or semi-sterile eggs and so will not contribute to the next generation of mosquitoes (Seawright et al. 1977; Benedict and Robinson 2003; Bellini 2005; Helinski et al. 2006; Bellini et al. 2007; Brelsfoard and Dobson 2009; Helinski and Knols 2009; Bellini et al. 2013a, 2013b; Balestrino et al. 2014). SIT complements the use of environmental management and products based on Bti in an ideal manner because no traditional insecticides are used and the most selective control tools are applied. The defined island-like occurrence of Ae. albopictus in Germany in combination with limited migration behaviour favours the use of SIT in an integrated control programme. Furthermore, metallic copper spray could be used to impregnate grave vases as frequent breeding sites of $A e$. albopictus when a threat to the public exists. Metallic copper sprayed on the interior surface of vases provides a long-term effect and kills newly hatching larvae for up to 3 months (Becker et al. 2015).

Successful control can only be achieved when all effective control tools are carefully implemented and all breeding sites can be accessed. The cooperation of the authorities and the public is essential to be able to inspect all properties.
Acknowledgements We acknowledge gratefully the contributions of Klaus Hoffmann and Jochen Gubener for their support in preparing the figures; Dr. Mario Ludwig for his support in the statistical evaluations and Peter Friederich, Lilith Stelzner and Xenia Augsten as well as the board and the gardeners of the Hettlinger allotment garden area for their support in conducting the field work. We are thankful for the financial support of the Baden-Württemberg Ministry of Employment and Social Order, Family, Women and Elderly and the Institute for Dipterology (IfD). We are thankful for the support of Dr. Harald Gebhardt from the Baden-Württemberg State Institute for Environment, Measurements and Nature Conservation and Dr. Rainer Oehme, Baden-Württemberg State Health Authority.

Open Access This article is distributed under the terms of the Creative Commons Attribution 4.0 International License (http:// creativecommons.org/licenses/by/4.0/), which permits unrestricted use, distribution, and reproduction in any medium, provided you give appropriate credit to the original author(s) and the source, provide a link to the Creative Commons license, and indicate if changes were made.

\section{References}

Abbott WS (1925) A method of computing the effectiveness of an insecticide. J Econ Entomol 18:265-267

Adhami J, Reiter P (1998) Introduction and establishment of Aedes (Stegomyia) albopictus Skuse (Diptera: Culicidae) in Albania. J Am Mosq Control Assoc 14:340-343

Angelini R, Finarelli AC, Angelini P, Po C et al (2007) Chikungunya in North-Eastern Italy: a summing up of the outbreak. Euro Surveill 12(11):E071122.2

Balestrino F, Puggioli IA, Bellini R, Petrić D, Gilles JRL (2014) Mass production cage for Aedes albopictus (Diptera: Culicidae). J Med Entomol 51(1):155-163

Becker N (1992) Community participation in the operational use of microbial control agents in mosquito control programs. Bull Soc Vector Ecol 17(2):114-118

Becker N (2008) Influence of climate change on mosquito development and mosquito-borne diseases in Europe. Parasitol Res 103(Suppl 1): $19-28$

Becker N, Djakaria S, Kaiser A, Zulhasril O, Ludwig HW (1991) Efficacy of a new tablet formulation of an asporogenous strain of Bacillus thuringiensis israelensis against larvae of Aedes aegypti. Bull Soc Vector Ecol 16(1):176-182

Becker N, Petrić D, Zgomba M, Boase C, Madon M, Dahl C, Kaiser A (2010) Mosquitoes and their control. Springer, Heidelberg/ Dordrecht/London/New York, pp 577

Becker N, Pluskota B, Kaiser A, Schaffner F (2012) Exotic mosquitoes conquer the world. In: Mehlhorn H (ed) Arthropods as vectors of emerging diseases. Parasitology research monographs 3. SpringerVerlag, Berlin, pp. 31-60

Becker N, Oo TT, Schork N (2015) Metallic copper spray - a new control technique to combat invasive container-inhabiting mosquitoes. Parasites Vectors 8:575

Bellini R (2005) Applicazione della tecnica del maschio sterile nella lotta ad Aedes albopictus. Doctoral thesis, DiSTA-Università degli Studi di Bologna, Italy

Bellini R, Calvitti M, Medici A, Carrieri M, Celli G, Maini S (2007) Use of the sterile insect technique against Aedes albopictus in Italy: first results of a pilot trial. In: MJB V, Robinson AS, Hendrichs J (eds) Area-wide control of insect pests: from research to field implementation. Springer, Dordrecht, pp. 505-515 
Bellini R, Balestrino F, Medici A, Gentile G, Veronesi R, Carrieri M (2013a) Mating competitiveness of Aedes albopictus radiosterilized males in large enclosures exposed to natural conditions. $\mathrm{J}$ Med Entomol 50(1):94-102

Bellini R, Medici A, Puggioli A, Balestrino F, Carrieri M (2013b) Pilot field trials with Aedes albopictus irradiated sterile males in Italian urban areas. J Med Entomol 50(2):317-325

Beltrame A, Angheben A, Bisoffi Z, Monteiro G, Marocco S, Calleri G (2007) Imported chikungunya infection, Italy. Emerg Infect Dis 13(8):1264-1266

Benedict MQ, Robinson AS (2003) The first releases of transgenic mosquitoes: an argument for the sterile insect technique. Trends Parasitol 19:349-355

Benedict MQ, Levine RS, Hawley WA, Lounibos LP (2007) Spread of the tiger: global risk of invasion by the mosquito Aedes albopictus. Vector Borne Zoonotic Dis 7(1):76-85

Biogents (2016a) Weltweit von Profis Verwendet: Die BG-Sentinel Stechmückenfalle. http://www.biogents.com

Biogents (2016b) BG-GAT (Gravid Aedes Trap) für Forscher. http://biogents.com

Brelsfoard CL, Dobson SL (2009) Wolbachia-based strategies to control insect pests and disease vectors. AsPac J Mol Biol. Biotechnol 17(3):55-63

Cornel AJ, Hunt RH (1991) Aedes albopictus in Africa? First records of live specimens in imported tires in Capetown. J Am Mosq Control Assoc 7:107-108

Dalla Pozza G, Majori G (1992) First record of Aedes albopictus establishment in Italy. J Am Mosq Control Assoc 8:318-320

DWD (2016) Deutscher Wetterdienst: Klima Freiburg. http://ftp-cdc. dwd.de/pub/CDC/observations-germany/climate

ECDC (2009) Development of Aedes albopictus risk maps. http://www. ecdc.europa.eu/en/publications/Publications/0905 TER Development of Aedes albopictus Risk Maps.pdf

ECDC (2012) Guidelines for the surveillance of invasive mosquito species in Europe. ECDC, Stockholm

EMCA-WHO (2013) Guidelines for the control of mosquitoes of public health importance in Europe. EMCA/WHO, Speyer, Germany. www.emca-online.eu

Finney DJ (1971) Probit analysis, 3rd edition, Cambridge Univ Press.

Folmer O, Black M, Hoeh W, Lutz R, Vrijenhoek R (1994) DNA primers for amplification of mitochondrial cytochrome $\mathrm{c}$ oxidase subunit 1 from diverse metazoan invertebrates. Mol Mar Biol Biotechnol 3: 294-299

Gratz NG (2004) Critical review of the vector status of Aedes albopictus. Med Vet Entomol 18:215-227

Gubler DJ, Bhattacharya NC (1971) Observations on the reproduction history of Aedes (Stegomyia) albopictus in the laboratory. Mosq News 31(3):356-359

Hawley WA (1988) The biology of Aedes albopictus. J Am Mosq Control Assoc 1(Suppl 4):1-39

Helinski MEH, Knols BGJ (2009) Sperm quantity and size variation in un-irradiated and irradiated males of the malaria mosquito Anopheles arabiensis Patton. Acta Trop 109(1):64-69

Helinski MEH, Parker AG, Knols BGJ (2006) Radiation-induced sterility for pupal and adult stages of the malaria mosquito Anopheles arabiensis. Malar J 5:41

Knudsen AB (1995) Global distribution and continuing spread of Aedes albopictus. Parassitologia 37:91-97

Köhler W, Schachtel G, Voleske P (1984) Biometrie. Springer Verlag, Berlin, Heidelberg, New York

Kroeger A, Dehlinger U, Burkhardt G, Anaya H, Becker N (1995) Community based dengue control in Columbia: people's knowledge and practice and the potential contribution of the biological larvicide Bti (Bacillus thuringiensis israelensis). Trop Med Parasitol 46:241246
Madon MB, Hazelrigg JE, Shaw MW, Kluh S, Mulla MS (2004) Has Aedes albopictus established in California? J Am Mosq Control Assoc 19:298

Medlock JM, Avanell D, Barrasss L, Leach S (2006) Analysis of the potential survival and seasonal activity of Aedes albopictus (Diptera: Culicidae) in the United Kingdom. J Vector Ecol 31(2): 292-304

Medlock J, Hansford KM, Schaffner F, Versteirt V, Hendrickx G, Zeller $\mathrm{H}$, van Bortel W (2012) A review of the invasive mosquitoes in Europe: ecology, public health risks, and control options. Vector Borne Zoonotic Dis 12(6):435-447

Medlock J, Hansford KM, Versteirt V, Cull B, Kampen H, Fontenille D, Hendrickx G, Zeller H, van Bortel W, Schaffner F (2015) An entomological review of invasive mosquitoes in Europe. Bull Entomol Res 105:637-663

Mitchell CJ (1995) Geographic spread of Aedes albopictus and potential for involvement in arbovirus cycles in the Mediterranean basin. $\mathrm{J}$ Vector Ecol 20:44-58

Moore CG, Mitchell CJ (1997) Aedes albopictus in the United States: ten year presence and public health implications. Emerg Infect Dis 3: 329-334

Nawrocki SJ, Hawley WA (1987) Estimation of the northern limits of distribution of Aedes albopictus in North America. J Am Mosq Control Assoc 3(2):314-317

Pfeffer M, Loescher T (2006) Cases of Chikungunya imported into Europe. http://www.Europsurveillance.org

Phuanukoonnon S, Mueller I, Bryan JH (2005) Effectiveness of dengue control practices in household water containers in Northeast Thailand. Trop Med Int Health 10:755-763

Pluskota B (2011) Die Asiatische Tigermücke (Aedes albopictus): Thermale Ökologie und Risikoeinschätzung einer Etablierung in Deutschland. Ph.D. thesis, Faculty of Biology, University of Heidelberg

Pluskota B, Storch V, Braunbeck T, Beck M, Becker N (2008) First record of Stegomyia albopicta (Skuse) (Diptera: Culicidae) in Germany. Eur Mosq Bull 26:1-5

Pluskota B, Jöst A, Augsten X, Stelzner L, Ferstl I, Becker N (2016) Successful overwintering of Aedes albopictus in Germany. Parasitol Res 115(8):3245-3247. doi:10.1007 /s00436-016-5078-2

Raymond M (1985) Presentation d'un programme d'analyse log-probit pour micro-ordinateur. Cah ORSTOM. Ser Ent Med Parasitol 22: $117-121$

Reiter P, Sprenger D (1987) The used tire trade: a mechanism for the worldwide dispersal of container breeding mosquitoes. J Am Mosq Control Assoc 3:494-501

Reiter P, Fontenille D, Paupy C (2006) Aedes albopictus as an epidemic vector of Chikungunya virus: another emerging problem? Lancet Infect Disease 6:463-464

Rezza G, Nicoletti L, Angelini R, Romi R et al (2007) Infection with CHIKV in Italy: an outbreak in a temperate region. Lancet 370(9602):1840-1846

Roiz D, Eritja R, Molina-Alcibar R, Lucientes J (2008) Distribution assessment of Aedes albopictus (Diptera: Culicidae) in the Barcelona area, Spain. J Med Entomol 45(3):347-352

Roiz D, Neteler M, Castellani C, Arnoldi D, Rizzoli A, Baylis M (2011) Climatic factors driving invasion of the tiger mosquito (Aedes albopictus) into new areas of Trentino, northern Italy. PLoS One 6(4):e14800

Romi R (1994) Aedes albopictus in Italia: problemi sanitari, strategie di controllo e aggiornamento della distribuzione al 30 settembre 1994. Notiziario ISS 7:7-11

Romi R (1995) History and updating on the spread of Aedes albopictus in Italy. Parassitologia 37:99-103 
Sabatini A, Raineri V, Trovato G, Coluzzi M (1990) Aedes albopictus in Italy and possible diffusion of the species into the Mediterranean area. Parassitologia 32:301-304

Scholte EJ, Schaffner F (2007) Waiting for the tiger: establishment and spread of the Aedes albopictus mosquito in Europe. In: Takken W, BGJ K (eds) Emerging pests and vector-borne diseases in Europe. Ecology and control of vector-borne diseases, vol 1. Wageningen Academic Publishers, Wageningen, pp. $241-260$

Seawright JA, Kaiser PE, Dame DA (1977) Mating competitiveness of chemosterilised hybrid males of Aedes aegypti (L.) in field tests. Mosq News 37(4):615-619

Skovmand O, Becker N (2000) Bioassays of Bacillus thuringiensis subsp. israelensis. In: Navon A, Ascher K (eds) Bioassays of Entomopathogenic microbes and nematodes. CABI Publishing, New York, pp. 41-47
Takumi K, Scholte EJ, Braks M, Reusken C, Avenell D, Medlock JM (2009) Introduction scenarios for establishment and seasonal activity of Aedes albopictus in the Netherlands. Vector Borne Zoonotic Dis 9:191-196

Toma L, Severini F, Luca MD, Bella A, Romi R (2003) Seasonal pattern of oviposition and egg hatching rate of Aedes albopictus in Rome. J Am Mosq Control Assoc 19(1):19-22

Werner D, Kampen H (2015) Aedes albopictus breeding in southern Germany, 2014. Parasitol Res 114:831-834

WHO (1981) Report of informal consultation on standardization of Bacillus thuringiensis $\mathrm{H}-14$. TDR/BCV/BTH-14/811, WHO/VBC/ 811-828

WHO (1999) Bacillus thuringiensis, environ health criteria 217. WHO, Geneva 